\title{
RANCANG BANGUN STRATEGI PEMBERDAYAAN UMKM MELALUI WAKAF PRODUKTIF BERBASIS MODEL SHARIA GRAMEEN BANK DI ERA NEW NORMAL
}

\author{
${ }^{1}$ Abd. Wahab \\ ${ }^{1}$ Siti Masfufa \\ ${ }^{2}$ Ridan Muhtadi \\ ${ }^{3}$ Nur Rachmat Arifin \\ ${ }^{1}$ Universitas Trunojoyo Madura \\ Jl. Raya Telang, Perumahan Telang Inda, Telang, Kamal, Kabupaten Bangkalan, \\ ${ }^{2}$ IAI Miftahul Ulum Pamekasan \\ Komplek PP. Miftahul Ulum Penyepen, Kabupaten Pamekasan, Jawa Timur \\ ${ }^{3}$ Universitas Islam Zainul Hasan Genggong \\ Jl. PB. Sudirman No. 360 Semampir Kraksaan Probolinggo \\ 1abdw06297@gmail.com \\ 1niefufa@gmail.com \\ ${ }^{2}$ ridanmuhtadi@gmail.com \\ ${ }^{3}$ nurrachmatarifin05@gmail.com
}

\begin{abstract}
Economic conditions in the midst of the Covid-19 pandemic, the people of Bira Tengah Village, Sampang Regency, have not been able to achieve a level of welfare even though in the village there is tourism potential for Lon Malang Beach and abundant marine products. The majority of housewives in the area do not have income-generating jobs. Thus, a solution is needed to optimize the role of housewives in the village to improve their economy in this new normal era. The purpose of this research is to create a solution idea in revitalizing the community's economy in order to alleviate poverty and increase the role of housewives in Central Bira in the new normal era. In writing this scientific paper, it uses research methods with a qualitative descriptive approach, data collection by interviews and literature studies as data sources. The concept of Sharia Grameen Bank is a model of Islamic microfinance institutions that apply sharia economic principles by utilizing capital from cash waqf and partnering with cooperatives supported by the use of the LOL website (Lon Malang Luminous Heaven) which can optimize the implementation process of Sharia Grameen Bank implementation). LOL (Lon Malang Luminous Heaven) is a website that is used as a medium in raising and distributing funds from productive waqf empowerment programs through cooperatives with murabahah contracts to housewives business groups in Central Bira.
\end{abstract}

Keywords: Poverty, LOL (Lon Malang Luminous Heaven), Sharia Grameen Bank, Productive Waqf.

\begin{abstract}
ABSTRAK
Kondisi perekonomian di tengah pandemi Covid-19 masyarakat Desa Bira Tengah Kabupaten Sampang, belum mampu mencapai taraf kesejahteraan sekalipun di desa tersebut terdapat potensi wisata Pantai Lon Malang maupun hasil laut yang melimpah. Para ibu rumah tangga di daerah tersebut mayoritas tidak memiliki pekerjaan yang menghasilkan pendapatan. Sehingga, dibutuhkan sebuah solusi untuk mengoptimalkan peran ibu rumah tangga di desa tersebut untuk meningkatkan perekonomiannya di era new normal ini. Tujuan dari penelitian ini adalah untuk menciptakan sebuah gagasan solutif dalam merevitalisasi ekonomi masyarakat guna mengentaskan kemiskinan serta meningkatkan peran ibu rumah tangga di Bira
\end{abstract}


${ }^{1}$ Abd. Wahab, ${ }^{1}$ Siti Masfufa, ${ }^{2}$ Ridan Muhtadi, ${ }^{3}$ Nur Rachmat Arifin

Tengah di era new normal. Dalam penulisan karya tulis ilmiah ini menggunakan metode penelitian dengan pendekatan deskriptif kualitatif, pengambilan data dengan wawancara dan studi literatur sebagai sumber datanya. Konsep Sharia Grameen Bank merupakan sebuah model lembaga keuangan mikro syariah yang menerapkan prinsip ekonomi syariah dengan memanfaatkan pemodalan dari wakaf tunai dan bermitra dengan koperasi yang didukung dengan penggunaan website LOL (Lon Malang Luminous Heaven) yang dapat mengoptimalkan proses pelaksanaan implementasi Sharia Grameen Bank). LOL (Lon Malang Luminous Heaven) merupakan website yang digunakan sebagai media dalam penggalangan dan penyaluran dana dari program pemberdayaan wakaf produktif melalui koperasi dengan akad murabahah kepada kelompok usaha ibu rumah tangga di Bira Tengah.

Kata Kunci: Kemiskinan, LOL (Lon Malang Luminous Heaven), Sharia Grameen Bank,Wakaf Produktif. 
Rancang Bangun Strategi Pemberdayaan UMKM melalui Wakaf Produktif Berbasis Model Sharia Grameen Bank di Era New Normal

\section{PENDAHULUAN}

Masalah besar yang hingga saat ini dihadapi oleh sebagian besar negara berkembang adalah kemiskinan. Oleh karena itu, Masalah kemiskinan memperoleh perhatian utama di Indonesia.

Grafik 1. Jumlah (Juta Orang) dan Persentase Penduduk Miskin di Indonesia

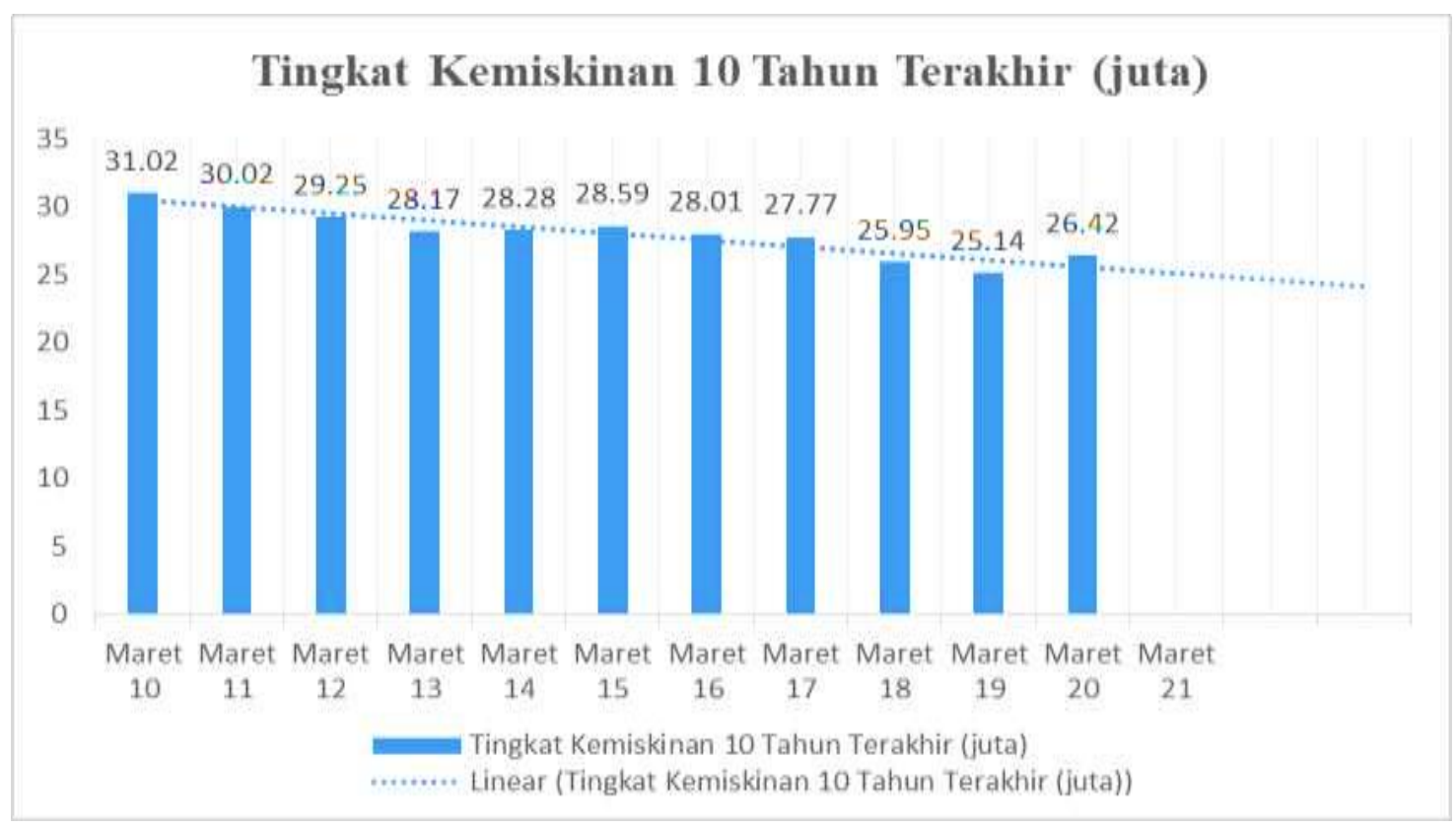

Pada grafik 1, jumlah penduduk miskin pada Maret 2020 meningkat dari pada periode sebelumnya. Pandemi Covid-19 turut menjadi alasan utama meningkatnya kemiskinan dan kemunduran pertumbuhan perekonomian nasional. Salah satu wujud dampak adanya pandemi Covid-19 tersebut juga dirasakan nelayan yaitu harga ikan yang menurun drastis hingga mencapai angka 50 persen, tentu tidak sebanding dengan tenaga yang dikeluarkan saat melaut dan tingginya biaya operasional serta cuaca buruk.

Bira Tengah merupakan salah satu desa yang terletak di Kecamatan Sokobanah, Kabupaten Sampang, Provinsi Jawa Timur. Desa Bira Tengah terletak di sebelah utara Kabupaten Sampang. Desa Bira Tengah pada bagian utaranya berbatasan dengan Laut Jawa. Dengan demikian, banyak potensi yang dimiliki oleh desa tersebut. yakni potensi wisata dengan dengan adanya Pantai Lon Malang, dan potensi hasil laut untuk diperdagangkan karena banyak kapal melaju di jalur tersebut. Berdasarkan data dari Kesekretariatan Desa Bira Tengah, desa ini memiliki jumlah nelayan sebanyak 311 (tiga ratus sebelas) orang (Data Primer, 2021). Namun dengan adanya berbagai potensi yang dimiliki, kondisi perekonomian di daerah Bira Tengah masih tergolong rendah, hal ini terbukti berdasarkan hasil wawancara yang telah dilakukan pada tanggal 18 Juli 2021. 
${ }^{1}$ Abd. Wahab, ${ }^{1}$ Siti Masfufa, ${ }^{2}$ Ridan Muhtadi, ${ }^{3}$ Nur Rachmat Arifin

Tabel 1. Hasil Wawancara Desa Bira Tengah, Kec. Sokobanah Kab. Sampang

\begin{tabular}{|l|l|r|r|}
\hline \multicolumn{1}{|c|}{ Responden } & \multicolumn{1}{c|}{ Jenis Pekerjaan } & Pendapatan & Pengeluaran Total \\
\hline Responden 1 & Nelayan & Rp. 2.000 .000 & Rp. 2.376 .000 \\
\hline Responden 2 & Pencari Ikan & Rp. 900.000 & Rp. 1.200 .000 \\
\hline Responden 3 & Petani Tambak & Rp. 1.500 .000 & Rp. 1.646 .500 \\
\hline Responden 4 & Nelayan & Rp. 1.000 .000 & Rp. 1.513 .500 \\
\hline Responden 5 & Nelayan & Rp. 950.000 & Rp. 1.056 .500 \\
\hline Responden 6 & Pencari Ikan & Rp. 1.250 .000 & Rp. 1.110 .000 \\
\hline Responden 7 & Pencari tambak & Rp. 1.250 .000 & Rp. 1.622 .700 \\
\hline Responden 8 & Nelayan & Rp. 1.500 .000 & Rp. 1.550 .000 \\
\hline
\end{tabular}

Sumber : Hasil Wawancara Penulis

Berdasarkan wawancara tersebut, sebagian besar dari responden terdapat suatu kondisi dimana istri dari nelayan hanya berperan sebagai ibu rumah tangga atau dalam kata lain yakni tidak memiliki pendapatan dari hasil kerjanya. Dengan kondisi pendapatan nelayan yang tidak pasti dan justru menurun akibat pandemi Covid-19, maka istri nelayan bisa membantu suami mereka untuk memperbaiki kondisi ekonomi keluarga dengan berwirausaha. Potensi ini dipandang paling menarik untuk dikaji yakni potensi ibu rumah tangga yang dapat membantu meningkatkan kesejahteraan ekonomi keluarga.

Indonesia memiliki potensi untuk merevitalisasi perekonomian di era new normal ini melalui dana wakaf. Potensi wakaf produktif di Indonesia sangat besar karena didukung oleh jumlah penduduk muslimnya. Berdasarkan data dari PewResearch Center, penduduk muslim di Indonesia pada tahun 2010 berjumlah 204 juta jiwa dan pada tahun 2030 diproyeksikan akan mencapai 238 juta jiwa. Selain itu, berdasarkan data yang dilansir pada kompasiana.com oleh Hida Hiyanti, dkk (2020) menyebutkan bahwa menurut M. Nuh selaku Ketua Badan Wakaf Indonesia potensi wakaf di Indonesia mencapai 77 triliun pertahun. Akan tetapi, dalam penghimpunan, pengelolaan, dan realisasi penerimaan wakaf masih menemui berbagai permasalahan yaitu seperti yang dilakukan oleh lembaga amal atau lembaga nazhir besar di Indonesia, misalnya Dompet Dhuafa, Aksi Cepat Tanggap (ACT), dan PKPU human initiative pada tahun 2017 baru 160 miliar dana wakaf yang berhasil terealisasi untuk kepentingan masyarakat.

Untuk mengatasi berbagai permasalahan yang ada, maka diperlukan solusi nyata yang relevan dan terkini. Solusi dari persoalan tersebut ialah LOL (Lon Malang Luminous Heaven). LOL (Lon Malang Luminous Heaven) adalah rancang bangun sistem monitoring dan evaluasi dalam strategi pemberdayaan UMKM melalui wakaf produktif pada ibu rumah tangga di era new 
Rancang Bangun Strategi Pemberdayaan UMKM melalui Wakaf Produktif Berbasis Model Sharia Grameen Bank di Era New Normal

normal dengan menerapkan model sharia grameen bank. Gagasan atau konsep ini merupakan sebuah upaya untuk meningkatkan peran ibu rumah tangga melalui program pembiayaan berbasis syariah, pembinaan dan pendampingan dalam menjalankan kegiatan usahanya. Dengan memanfaatkan kemajuan teknologi, permodalan dan pembiayaan dilakukan melalui program wakaf produktif untuk dijadikan modal dalam membangun Unit Mikro Kecil Menengah (UMKM) yang membutuhkan dana melalui LMI sebagai penyedia bahan (entitas) dengan akad murabahah. Implementasi konsep Sharia Grameen Bank ini melibatkan beberapa stakeholders, diantaranya pemerintah, akademisi, LMI Sampang, media, dan masyarakat sehingga diharapkan mampu meningkatkan kesejahteraan penduduk Desa Bira Tengah.

\section{KAJIAN PUSTAKA}

\section{Pemberdayaan Masyarakat}

Pemberdayaan berasal dari penerjemahan Bahasa Inggris yaitu "empowerment", yang bermakna "pemberian kekuasaan" karena power bukan sekedar "gaya" tapi juga merupakan "kekuasaan", sehingga kata "daya" tidak hanya bermakna "mampu" tapi juga "mempunyai kuasa" (Dwidjowijoto., 2007). Dwidjowijoto (2007) mengemukakan bahwa "konsep pemberdayaan masyarakat mencakup pengertian community development (pembangunan masyarakat) dan community based development (pembangunan yang bertumpu pada masyarakat), dan tahap selanjutnya muncul istilah community driven development yang diterjemahkan sebagai pembangunan yang diarahkan masyarakat atau diistilahkan sebagai pembangunan yang digerakkan oleh masyarakat..." "Konsep empowerment (pemberdayaan) sebagai konsep alternative pembangunan yang pada intinya menekankan pada otonomi pengambilan keputusan dari suatu kelompok masyarakat yang berlandaskan pada sumber daya pribadi, langsung melalui partisipasi, demokratis, dan pembelajaran sosial melalui pengalaman langsung...” (Dwidjowijoto., 2007). Pemberdayaan masyarakat merupakan upaya mempersiapkan masyarakat seiring dengan upaya memperkuat kelembagaan masyarakat agar rakyat mampu mewujudkan kemajuan, kemandirian, dan kesejahteraan dalam suasana keadilan sosial yang berkelanjutan. Selain itu, pemberdayaan masyarakat juga merupakan upaya meningkatkan harkat dan martabat masyarakat yang dalam kondisi sekarang mengalami kesulitan untuk melepaskan diri dari perangkap kemiskinan dan keterbelakangan. Dengan kata lain, pemberdayaan adalah memampukan dan memandirikan masyarakat. 
${ }^{1}$ Abd. Wahab, ${ }^{1}$ Siti Masfufa, ${ }^{2}$ Ridan Muhtadi, ${ }^{3}$ Nur Rachmat Arifin

Dalam jurnal Empowerment and Poverty Reduction : a sourcebook Empowerment and Development Effectiveness: Good Governance and Growth oleh Narayan-Parker (2002) mengemukakan bahwa: Empowerment is the expansion of assets and capabilities of poor people to participate in, negotiate with, influence, control, and hold accountable institutions that affect their lives.(Dengan adanya pemberdayaan maka orang-orang lemah dapat memperluas kemampuannya untuk berpartisipasi di dalam merundingkan, mempengaruhi, mengawasi dan mempertanggungjawabkan lembaga yang mempengaruhi kehidupan mereka)

"...Pemberdayaan pada hakekatnya adalah untuk menyiapkan masyarakat agar mereka mampu dan mau secara aktif berpartisipasi dalam setiap program dan kegiatan pembangunan yang bertujuan untuk memperbaiki mutu hidup (kesejahteraan) masyarakat, baik dalam pengertian ekonomi, sosial, fisik, maupun mental...”(Odagiri et al., 2020).

\section{Kemiskinan dan Model Grameen Bank}

Berawal dari kegelisahannya terhadap kondisi sosial masyarakat Bangladesh kala itu, dimana terdapat fakta bahwa seorang perempuan desa dapat secara tidak langsung menjadi "budak belian" Seorang rentenir hanya karena pinjaman uang sebesar tak lebih dari US\$1, Prof. Muhammad Yunus akhirnya mengambil keputusan yang berat dalam hidupnya. Sebuah keputusan yang pada akhirnya membawa angin segar bagi masyarakat yang tergolong kaum miskin. Grameen Bank, bank yang awal mulanya didirikan di Bangladesh pada tahun 1983, kini telah berkembang dan ditiru di lebih dari 100 negara di 5 benua.

Muhammad Yunus mendirikan Grameen Bank dengan alasan untuk memerangi kemiskinan. Salah satu solusi yang bisa dilakukan adalah dengan memberikan kredit usaha bagi kaum miskin melalui lembaga perbankan. Berbeda dengan bank umum yang tidak memberikan kredit kepada masyarakat yang tidak memiliki agunan, Grameen Bank yang dirintis Muhammad Yunus tidak memerlukan agunan dalam pemberian kreditnya. Grameen Bank menargetkan usahawan miskin yang tidak mampu meminjam kredit dari bank umum dengan memberikan mereka pinjaman berskala kecil (Yunus, 2013).

\section{Wakaf Produktif}

Dalam UU RI No. 41 Tahun 2004 tentang wakaf, dijelaskan bahwa wakaf adalah perbuatan yang dilakukan oleh wakif (orang yang berwakaf) untuk memberikan dan/atau memisahkan sebagian harta benda yang dimiliki untuk dimanfaatkan dalam kepentingan ibadah amaliyah 
Rancang Bangun Strategi Pemberdayaan UMKM melalui Wakaf Produktif Berbasis Model Sharia Grameen Bank di Era New Normal

dan/atau kesejahteraan umat dalam jangka waktu tertentu sesuai kesepakatan atau selamanya yang dalam pelaksanaannya sesuai dengan prinsip syariah (Mursyid, 2017).

Seiring berkembangnya zaman, pemanfaatan wakaf menjadi beraneka ragam yang salah satunya adalah wakaf langsung dan wakaf produktif (Qahaf, 2008). Wakaf langsung adalah wakaf yang diberikan langsung kepada orang yang membutuhkan. Sedangkan, wakaf produktif adalah jenis pemanfaatan wakaf yang tujuannya digunakan untuk kemaslahatan umat melalui modelmodel ekonomi yang produktif, sehingga manfaat dari harta wakaf itu sendiri dapat dimanfaatkan untuk sesuatu yang berdaya guna secara optimal dan berkesinambungan. Kemudian, hasil dari pengembangan wakaf berupa keuntungan bersih akan diberikan sesuai tujuan wakaf. Wakaf produktif sendiri dapat berupa wakaf uang yang mana pada tahun 2002 melalui Majelis Ulama Indonesia (MUI), telah mengeluarkan fatwa tentang diperbolehkannya wakaf uang (wakaf tunai). Dalam perealisasiannya, setidaknya wakaf produktif memiliki empat azaz pertimbangan, yaitu azaz keabadian manfaat, azaz pertanggung-jawaban, azaz profesionalitas manajemen, dan azaz keadilan sosial (Gunawan Aji, 2019). Dengan adanya potensi besar dari instrumen wakaf, maka sudah semestinya Indonesia memanfaatkan dengan sebaik mungkin keberadaan wakaf terutama wakaf produktif.

\section{METODE PENELITIAN}

Dalam penelitian ini menggunakan pendekatan kualitatif dengan jenis penelitian deskriptif. Tujuan penelitian kualitatif adalah untuk mendeskripsikan dan menganalisis fenomena, peristiwa, aktivitas sosial, sikap, kepercayaan, persepsi, pemikiran orang secara individual maupun kelompok. Data yang digunakan yaitu data primer dan sekunder, data sekunder merupakan data yang diperoleh dari sumber-sumber terkait seperti buku, jurnal dan lain-lain, sedangkan data primer diperoleh melalui hasil wawancara. Kuesioner adalah daftar pertanyaan yang telah disusun sedemikian rupa guna mendapatkan data yang dibutuhkan dan dilakukan melalui bertatap muka, telepon, atau surat (Ferdinand, 2006). Sementara itu, metode wawancara digunakan sebagai cara pengambilan data yang apabila peneliti ingin melakukan studi pendahuluan untuk menemukan berbagai permasalahan yang terjadi dan juga apabila peneliti ingin mengetahui hal-hal lebih lengkap dan mendalam dari responden dengan jumlah responden yang kecil atau sedikit (Sugiyono, 2014) Setelah dikumpulkan kemudian data diolah dengan menguraikan data dalam bentuk kalimat yang logis, urut, teratur, efektif serta tidak tumpang tindih sehingga memudahkan pemahaman dan interpretasi terhadap data yang ada. Lalu dianalisis dengan teknik analisis mendalam (indept analysis). Analisis mendalam digunakan untuk mengkaji masalah dari satu 
${ }^{1}$ Abd. Wahab, ${ }^{1}$ Siti Masfufa, ${ }^{2}$ Ridan Muhtadi, ${ }^{3}$ Nur Rachmat Arifin

kasus ke kasus yang lain karena dengan menggunakan pendekatan deskriptif-kualitatif yakin bahwa sifat suatu masalah akan berbeda dengan sifat dari masalah yang lainnya. Penelitian ini dilakukan selama 3 Bulan yakni September-November 2021 yang bertempat di Desa Bira Tengah, Kecamatan Sokobanah, Kabupaten Sampang.

\section{PEMBAHASAN}

\section{Gambaran Umum Konsep LOL (Lon Malang Luminous Heaven)}

Berawal dari permasalahan ekonomi yang dihadapi oleh masyarakat Desa Bira Tengah di masa pandemi Covid-19 dimana pendapatan yang rendah serta kesulitan dalam mengembangkan usahanya. Kemudian dengan adanya potensi wakaf produktif yang ada di LMI Sampang, maka sebagai generasi muda sudah semestinya membentuk solusi nyata. LOL (Lon Malang Luminous Heaven) merupakan rancang bangun strategi untuk memberdayakan masyarakat Desa Bira Tengah yang notabene sebagai UMKM melalui potensi wakaf produktif yang ada di daerah tersebut dengan mengadopsi sistem Grameen Bank serta menerapkan prinsip syariah melalui mitra dengan Laznas LMI Sampang, dan akademisi. Dalam wujud implementasi gagasan ini membutuhkan peran berbagai pemangku kepentingan yang akan saling bersinergi satu sama lain untuk mencapai tujuan yang telah ditetapkan sebelumnya. Adapun skema dari sinergitas stakeholders tergambar pada bagan berikut:

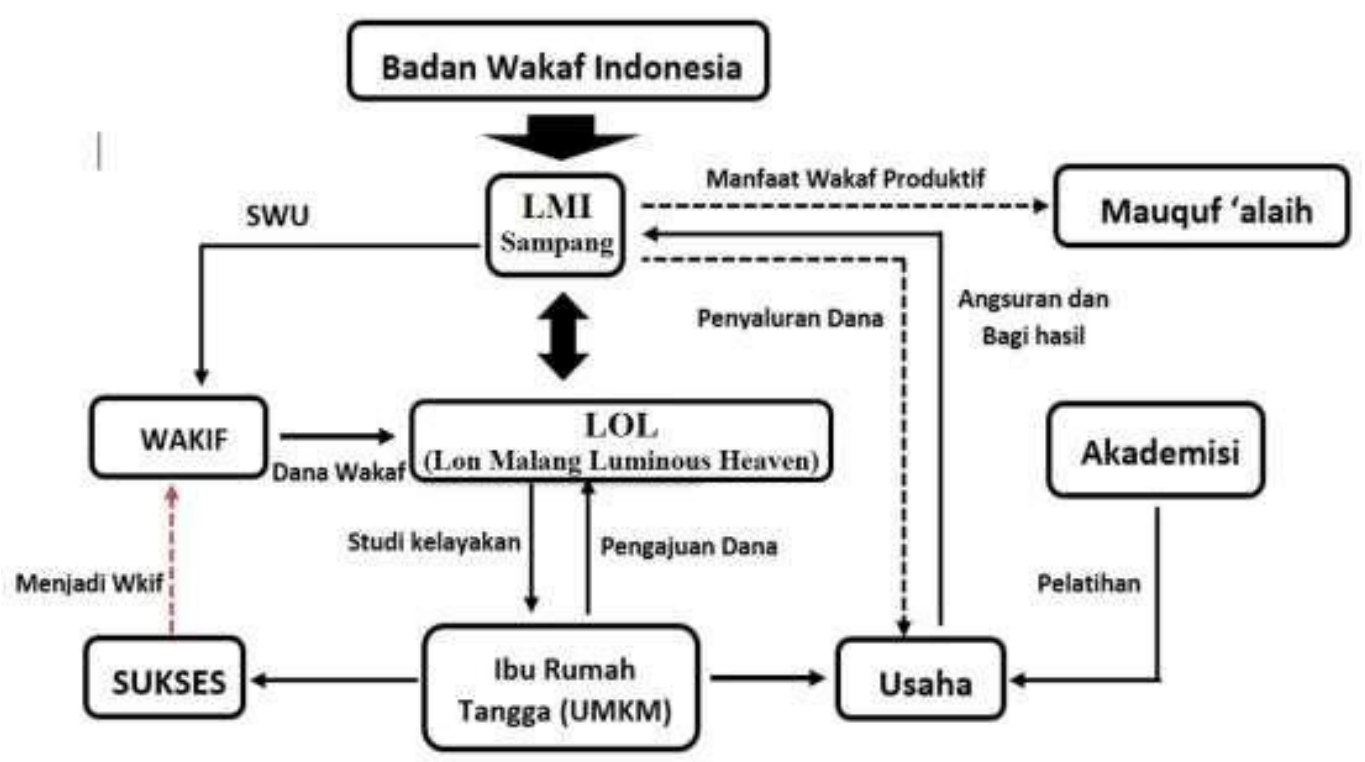

Gambar 1. Skema Sinergitas Stakeholders LOL (Lon Malang Luminous Heaven) 
Rancang Bangun Strategi Pemberdayaan UMKM melalui Wakaf Produktif Berbasis Model Sharia Grameen Bank di Era New Normal

Berdasarakan Gambar 1. Adapun penjelasannya adalah sebagai berikut:

1. Badan Wakaf Indonesia

Dalam hal ini berperan sebagai fasilitator yang memberikan fasilitas-fasilitas terhadap para nadzir (LMI Sampang), wakif, calon wakif, pengembangan, pelaporan dan pengawasan harta benda wakaf di Indonesia.

2. Wakif

Merupakan orang atau masyarakat umum yang memiliki kesanggupan dalam melaksanakan wakaf (orang yang berwakaf).

3. Laznas LMI Sampang

Dalam hal ini sebagai Nazir atau pengelola harta wakaf, merupakan pihak yang akan menampung serta mengelola wakaf secara produktif. Wakaf dari masyakarat umum (wakif) yang kemudian disalurkan melalui website. Harta wakaf yang telah diserahkan melalui website akan secara langsung masuk ke nomor rekening Laznas LMI Sampang.

4. Website LOL (Lon Malang Luminous Heaven)

Merupakan media yang menjembatani antara (wakif, Nadzir, dan Ibu rumah tangga) dalam menyebarluaskan info layanan untuk berwakaf secara online serta media dalam memberikan pinjaman modal berupa pembiayaan kepada kelompok usaha ibu rumah tangga Desa Bira Tengah.

5. Ibu Rumah Tangga

Ibu rumah tangga kemudian yang terdaftar dalam website, sebagai penerima dana dari wakaf tersebut untuk mengembangkan usahanya. Dalam proses tersebut, ibu rumah tangga mengajukan pembiayaan melalui website yang tersedia beserta melampirkan berkas-berkas yang telah ditentukan. Setelah terdata di website kemudian sistem akan mengirimnya ke LMI Sampang guna Acc dan penyaluran modal. Setelah mendapatkan pinjaman modal, ibu rumah tangga akan dilatih dan didampingi dalam menjalankan usahanya. Selanjutnya uang pokok dari wakaf beserta keuntungan dari pembiayaan (atau menggunakan akad murabahah) akan dikembalikan pada LMI Sampang dan 90\% dari keuntungan akan disalurkan kepada mauquf ,,alaih. Ibu rumah tangga Penduduk Desa Tengah memiliki peran yang sangat vital, karena merekalah yang menjadi kunci keberhasilan dari kegiatan usaha dari program LOL(Lon Malang Luminous Heaven). 
${ }^{1}$ Abd. Wahab, ${ }^{1}$ Siti Masfufa, ${ }^{2}$ Ridan Muhtadi, ${ }^{3}$ Nur Rachmat Arifin

6. Akademisi

Akademisi berperan sebagai fasilitator yang memberikan edukasi sekaligus memberikan pendampingan dan pembinaan usaha kelompok debitur untuk meningkatkan kualitas usahanya. Hal tersebut juga menjadi sarana bagi para akademisi untuk melaksanakan kegiatan Tri Dharma Perguruan Tinggi yakni pendidikan, penelitian dan pengabdian masyarakat.

7. Mauquf 'alaih

Merupakan salah satu rukun wakaf yaitu orang yang menerima wakaf atau penerima manfat dari adanya wakaf tersebut. Dalam hal ini, mauquf ,alaih terdiri dari masyarakat Bira Tengah, atau sesuai daftar list mauquf ,,alaih yang sudah ada sebelumnya di LMI Sampang sebagai penerima manfaat dari adanya wakaf produktif.

Dalam implementasinya, kontribusi dari berbagai pihak yang telah disebutkan menjadi kunci kesuksesan program ususlan. Dimana ibu rumah tangga sebagai UMKM yang semula tidak memiliki kemampuan dalam mengembangkan usahanya akan didampingi hingga mampu dan berdaya. Dalam hal ini LMI sebagai nadzir akan mengelola wakafnya secara produktif dengan memberikan permodalan bagi para UMKM yang telah terverifikasi oleh sistem LOL. Para UMKM yang telah mendapatkan modal untuk pengembangan usahanya tidak dilepas begitu saja, akan tetapi melalui program di LOL akan diberikan pelatihan usaha, manajemen keuangan yang baik hingga pemasarannya. Pendampingan tersebut dilakukan secara berkesinambungan hingga UMKM mampu mengembalikan pinjaman modal beserta margin yang telah ditentukan sebelumnya. Artinya, ketika hal tersebut sudah tercapai maka UMKM sudah mampu meningkatkan usahanya dengan bertambahnya laba yang diperoleh.

Jika program ini terus dilakukan dan laba usaha akan terus bertambah, sehingga dampak positif yang ditimbulkan adalah kemampuan mengelola usaha UMKM mengalami peningkatan, akhirnya akan terbukanya lapangan pekerjaan dan ekonomi masyarakat sekitar meningkat. Ketika ekonomi masyarakat sudah mengalami peningkatan, harapannya adalah jika awalnya masyarakat kesulitan dalam modal usaha, maka saat ini mereka sudah mampu dan menjadi wakif atau orang yang berwakaf. Sehingga program ini menciptakan perputaran ekonomi serta berkesinambungan, kemudian masyarakat tidak lagi menjadi debitur atau mungkin sebelumnya sebagai mauquf,,alaih. 
Rancang Bangun Strategi Pemberdayaan UMKM melalui Wakaf Produktif Berbasis Model Sharia Grameen Bank di Era New Normal

Model Rancang Pelaksanaan konsep LOL (Lon Malang Luminous Heaven) pada Masyarakat Bira Tengah sebagai Strategi Pemberdayaan Wakaf Produktif di Era New Normal

Dalam pelaksanaan konsep LOL (Lon Malang Luminous Heaven) terdapat enam tahapan program yang dijalankan. Adapun skema pelaksanaan LOL (Lon Malang Luminous Heaven) terilustrasikan pada gambar berikut ini:

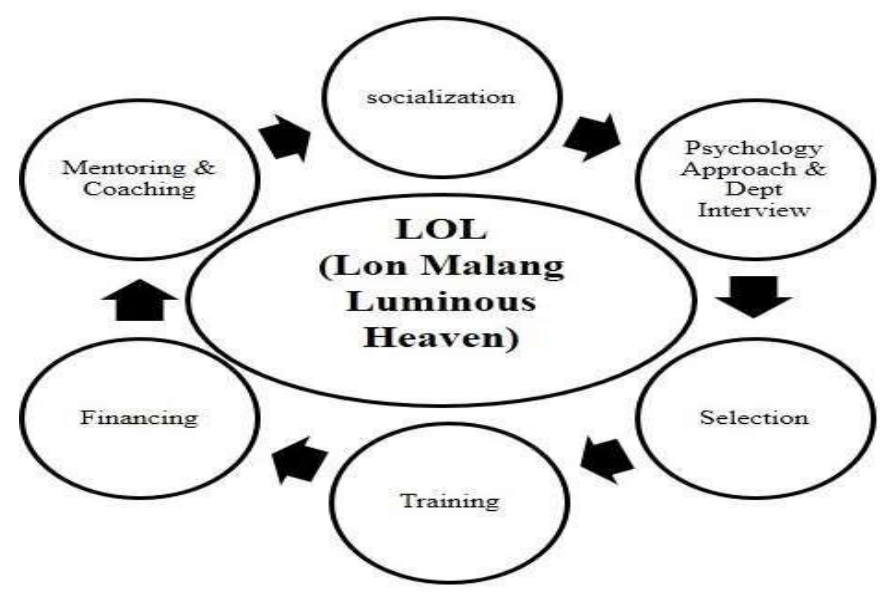

Gambar 2. Skema Tahapan Konsep LOL (Lon Malang Luminous Heaven)

Tabel 2. Penjelasan Tahapan Konsep LOL (Lon Malang Luminous Heaven

\begin{tabular}{|l|l|}
\hline \multicolumn{1}{|c|}{ Tahapan } & \multicolumn{1}{c|}{ Rincian Kegiatan } \\
\hline Sosialisasi & Kegiatan sosialisasi ini dilaksanakan bekerja sama dengan para akademisi \\
& $\begin{array}{l}\text { setempat serta pemerintah desa maupun pemerintah terkait. Sosialiasi ini } \\
\text { diberikan agar masyarakat dapat mengenal tentang pentingnya } \\
\text { mengoptimalkan potensi sumber daya yang ada melalui kegiatan produktif } \\
\text { yang dapat menghasilkan pendapatan sekalipun di tengah situasi pandemi } \\
\text { Covid-19. Selain itu, juga diberikan materi sosialisasi pemahaman dasar } \\
\text { mengenai sistem ekonomi syariah maupun tentang mekanisme konsep LOL } \\
\text { (Lon Malang Luminous Heaven). Dengan begitu masyarakat memiliki dasar } \\
\text { pemahaman sebagai bekal dalam melakukan kegiatan usaha nantinya. } \\
\text { Sosialisasi ini dilaksanakan dengan tetap menjaga dan mentaati protokol } \\
\text { kesehatan. Pengenalan platform berwakaf melalui LOL (Lon Malang } \\
\text { Luminous Heaven) juga dilakukan kepada masyarakat umum. }\end{array}$ \\
\hline
\end{tabular}




\begin{tabular}{|c|c|}
\hline $\begin{array}{l}\text { Pendekatan } \\
\text { Psikologi dan } \\
\text { Wawancara } \\
\text { Mendalam } \\
\text { (Psychology } \\
\text { Approach \& } \\
\text { Dept } \\
\text { Interview) }\end{array}$ & $\begin{array}{l}\text { Setelah dilakukan kegiatan sosialiasi, tahapan selanjutnya adalah pendekatan } \\
\text { psikologi dan wawancara mendalam kepada para calon penerima program } \\
\text { (pembiayaan). Konsep ini menggunakan pendekatan yang lebih mendalam } \\
\text { yang didasarkan pada keseriusan calon peminjam dalam mengajukan dan } \\
\text { memanfaatkan pinjaman. Karena konsep LOL (Lon Malang Luminous } \\
\text { Heaven) ini bertujuan untuk membantu masyarakat dalam meningkatkan } \\
\text { kesejahteraannya, maka sepenuhnya akan membantu usaha rumah tangga } \\
\text { yang belum memiliki usaha untuk bisa produktif dan untuk usaha yang telah } \\
\text { produktif akan ada pembinaan lebih lanjut guna membantu usaha kelompok } \\
\text { lain untuk bisa ikut produktif. }\end{array}$ \\
\hline $\begin{array}{l}\text { Tahap Seleksi } \\
\text { (Selection) }\end{array}$ & $\begin{array}{l}\text { Pada tahap ini akan dilakukan seleksi bagi para calon penerima pinjaman. } \\
\text { Aspek penting yang perlu digarisbawahi adalah dalam penyaluran dana } \\
\text { pembiyaan ini menitikberatkan kepada perempuan (ibu rumah tangga) desa } \\
\text { Bira Tengah sebagai sasaran. }\end{array}$ \\
\hline $\begin{array}{l}\text { Pelatihan } \\
\text { (Training) }\end{array}$ & $\begin{array}{l}\text { Selanjutnya diadakan pelatihan lanjutan mengenai kebijakan- kebijakan } \\
\text { (mekanisme pembiayaan, pengembalian dan terkait sanksi) serta prinsip- } \\
\text { prinsip yang harus dijalankan dalam kegiatan usaha. Selain itu, diberikan } \\
\text { juga pemahaman secara mendalam kepada para calon penerima pembiayaan } \\
\text { mengenai pentingnya program tersebut terhadap keberlangsungan usaha, } \\
\text { perbedaan antara LOL (Lon Malang Luminous Heaven) dengan sistem } \\
\text { pembiayaan lainnya (khususnya kredit pada bank konvensional dan } \\
\text { rentenir), pentingnya kebersamaan dalam kelompok peminjam, serta banyak } \\
\text { hal lain terkait usaha yang halal dan sesuai kaidah, dan juga beberapa hal } \\
\text { terkait ekonomi syariah yang terdapat dalam kehidupan sehari-hari. Kegiatan } \\
\text { ini diakhiri dengan test evaluasi untuk calon penerima pinjaman terkait } \\
\text { dengan materi yang telah diberikan. }\end{array}$ \\
\hline
\end{tabular}


Rancang Bangun Strategi Pemberdayaan UMKM melalui Wakaf Produktif Berbasis Model Sharia Grameen Bank di Era New Normal

\begin{tabular}{|c|c|}
\hline $\begin{array}{l}\text { Pendanaan } \\
\text { (Financing) }\end{array}$ & $\begin{array}{l}\text { Sesuai dengan metode yang digunakan pada website LOL (Lon Malang } \\
\text { Luminous Heaven), pinjaman akan diberikan atas nama kelompok usaha } \\
\text { dengan ketentuan sebagai berikut: } \\
\text { - Kelompok usaha akan dibantu pihak LOL (Lon Malang Luminous } \\
\text { Heaven) dalam melakukan pengajuan proposal pembiayaan secara } \\
\text { online di website LOL (Lon Malang Luminous Heaven). } \\
\text { - Masa pinjaman (1 periode) adalah } 1 \text { tahun } \\
\text { - Menggunakan akad murabahah dalam pencairan pendanaan dari } \\
\text { Laznas LMI Sampang kepada kelompok usaha. } \\
\text { Besarnya cicilan sebesar } 2 \% \text { dari total tanggungan per minggu selama } \\
50 \text { minggu ditamabah dengan margin } 20 \% \text { yang telah disepakati di } \\
\text { awal. Untuk Rp. } 1.000 .000 \text {,. ditambah dengan margin Rp. } 200.000 \\
\text { maka angsuran yang harus dibayar adalah Rp } 24.000,-/ \text { minggu selama } \\
50 \text { kali (untuk asumsi pinjaman } 1 \text { juta rupiah). Sehingga apabila } \\
\text { berkelompok maka tiap angggota dalam } 1 \text { minggu membayar Rp. } \\
4.800 . \text {., }\end{array}$ \\
\hline & $\begin{array}{l}\text { - Program ini mengutamakan solidaritas pada masing-masing anggota. } \\
\text { Sehingga, apabila ada salah satu anggota yang tidak mampu melunasi } \\
\text { kewajibannya, maka anggota yang lain harus membantunya. }\end{array}$ \\
\hline $\begin{array}{l}\text { Pembinaan } \\
\text { Dan } \\
\text { Pendampinga } \\
\text { n (Mentoring } \\
\text { \&Coaching) }\end{array}$ & $\begin{array}{l}\text { Pada tahap ini para kelompok usaha akan diberikan pembinaan dan } \\
\text { pendampingan dari lembaga secara berkala bekerja sama dengan akademisi } \\
\text { setempat sebagai fasilitator. Pembinaan dan pendampingan yang diberikan } \\
\text { berupa keterampilan managerial maupun operasional. Tujuannya adalah } \\
\text { agar keberlangsungan usaha dari kelompok debitur tersebut bisa terjaga dan } \\
\text { terus berlanjut. }\end{array}$ \\
\hline
\end{tabular}


Konsep operasional Website LOL.com dilakukan secara online. Berikut penjelasan operasional online LOL (Lon Malang Luminous Heaven) yang meliputi:

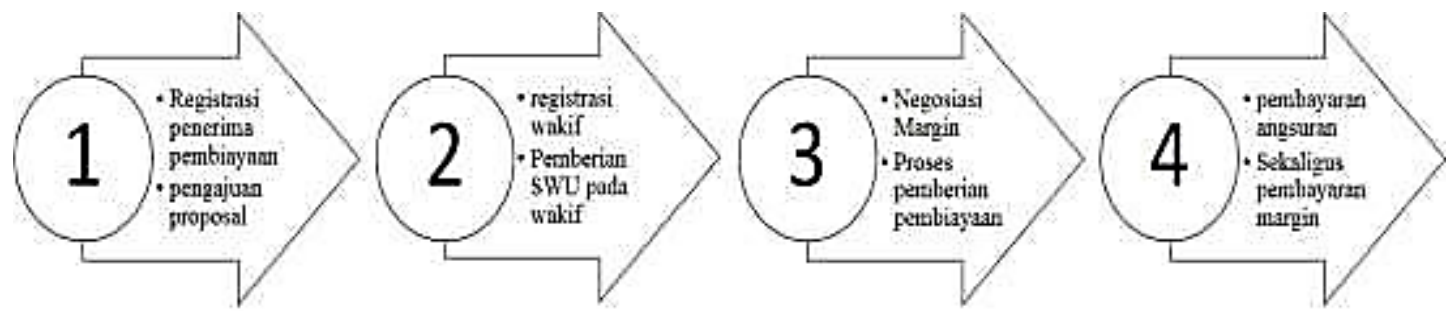

Gambar 3. Konsep Operasional Website LOL.com

1. Registrasi penerima modal dan proses pengajuan proposal pembiayaan.

Untuk menjadi penerima pembiayaan di website LOL.com syaratnya harus melalui prosedur tahapan pelaksanaan konsep LOL.com, mulai dari Tahap Sosialisasi (Socialization), Pendekatan Psikologi dan Wawancara Mendalam (Psychology Approach \& Dept Interview), Tahap Seleksi (Selection), Pelatihan (Training), Pendanaan (Financing) hingga kemudian ikut serta dalam Pembinaan dan Pendampingan (Mentoring \& Coaching).

\section{Registrasi wakif dan proses pemberian pembiayaan.}

Untuk menjadi wakif di LOL.com, terdapat syarat yang harus dipenuhi diantaranya adalah: perseorangan mapun institusi, untuk perseorangan minimal berusia 17 tahun yang dibuktikan dengan kartu identitas diri berupa KTP/SIM/Passpor. Selanjutnya untuk proses berwakaf pertama kali, wakif diharuskan melakukan pendaftaran online untuk menjadi anggota aktif di website LOL.com, dengan mengisi formulir pendaftaran di menu berwakaf. Wakif menyertakan data lengkap dan kontak yang bisa dihubungi. Selanjutnya, wakif menyetorkan dana wakaf. Dana tersebut yang nantinya akan digunakan untuk pembiayaan investasi kepada UMKM yang terdaftar di website LOL.com. Setelah melakukan transfer, secara otomatis akan tersimpan di saldo virtual rekening Laznas LMI Sampang.

Wakif yang telah mewakafkan hartanya dengan total minimal Rp. 1.000.000, maka wakif mendapatkan Sertifikat Wakaf Uang (SWU) sebagai bentuk apresiasi dan penghargaan. Wakif yang pernah mewakafkan hartanya, juga mendapatkan program bernama waqf reminder. Waqf reminder adalah program yang mana wakif akan diberi kata-kata motivasi islami dan pengingat untuk berwakaf yang akan dikirimkan melalui pesan pribadi ke nomor whatsapp wakif yang telah diisikan pada formulir pendaftaran 
Rancang Bangun Strategi Pemberdayaan UMKM melalui Wakaf Produktif Berbasis Model Sharia Grameen Bank di Era New Normal

saat menjadi anggota aktif terdahulu. Waqf reminder dilakukan rutin setiap seminggu sekali pada hari jum"at.

\section{Proses Negoisasi margin dan pemberian pembiayaan}

Proses negoisasi persetujuan akad jual beli dengan tambahan margin keuntungan sesuai dengan kesepakatan antara LMI Sampang dan UMKM dengan pembayaran ditangguhkan minimal 1 bulan sampai 1 tahun. Sesuai dengan metode yang digunakan pada website LOL.com dengan penerapan model Grameen Bank pinjaman akan diberikan atas nama kelompok usaha.

\section{Pembayaran angsuran sekaligus pembayaran margin}

Skema angsuran pembiayaan pokok dan pembayaran margin. Seperti yang sudah dijelaskan pada tabel 2 mengenai penjelasan tahapan konsep LOL (Lon Malang Luminous Heaven), Besarnya cicilan sebesar 2\% dari total tanggungan per minggu selama 50 minggu ditamabah dengan margin $20 \%$ yang telah disepakati di awal. Untuk Rp. 1.000.000,. ditambah dengan margin Rp. 200.000 maka angsuran yang harus dibayar adalah $\mathrm{Rp} 24.000,-/$ minggu selama 50 kali (untuk asumsi pinjaman 1 juta rupiah). Sehingga apabila berkelompok maka tiap angggota dalam 1 minggu membayar Rp. 4.800. Nantinya, uang angsuran tersebut dikoordinir dan dikumpulkan kepada ketua kelompok dari UMKM ibu rumah tangga. Ketua kelompok yang akan mentransfer uang angsuran dan margin kepada pihak Laznas LMI Sampang. Kemudian, hasil dari pengembangan wakaf produktif dari UMKM ibu rumah tangga ini yang disalurkan untuk kepentingan mauquf ,alaih, seperti bantuan pengembangan masjid, sekolah, fasilitas kesehatan, dan kepentingan sosial lainnya.

\section{Penjelasan Operasional Website LOL (Lon Malang Luminous Heaven)}

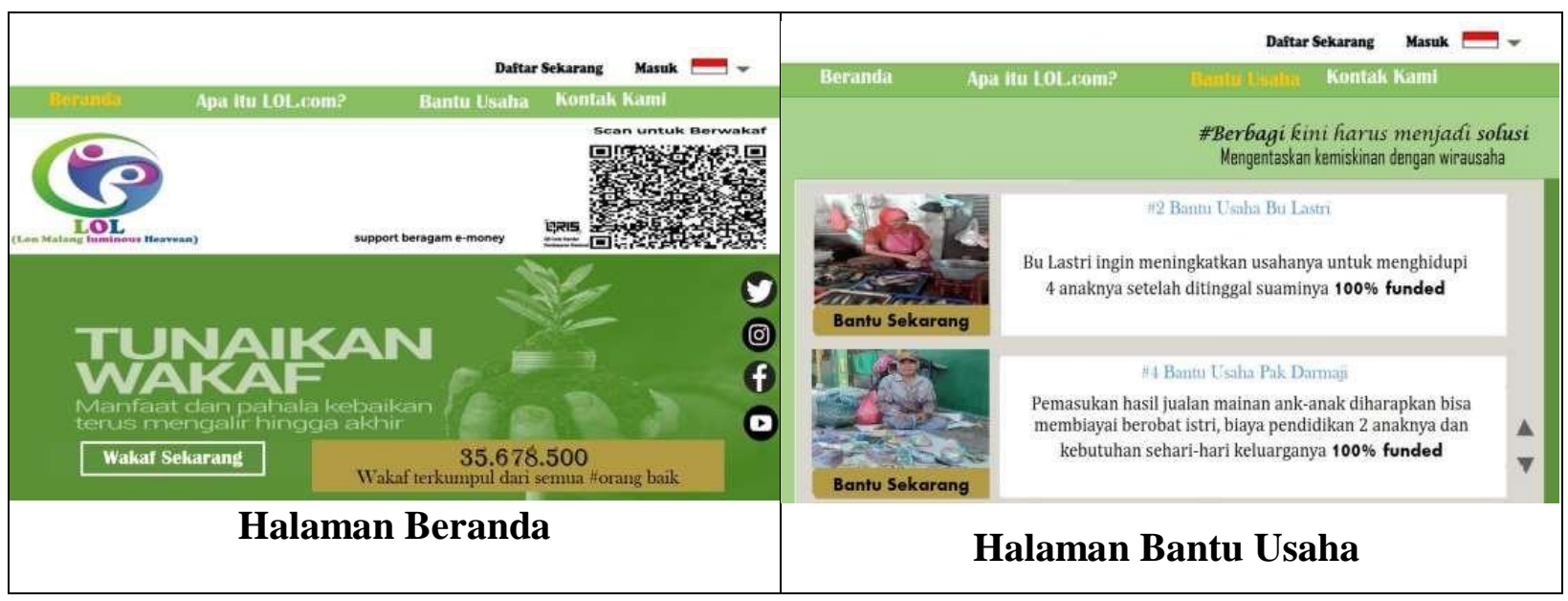




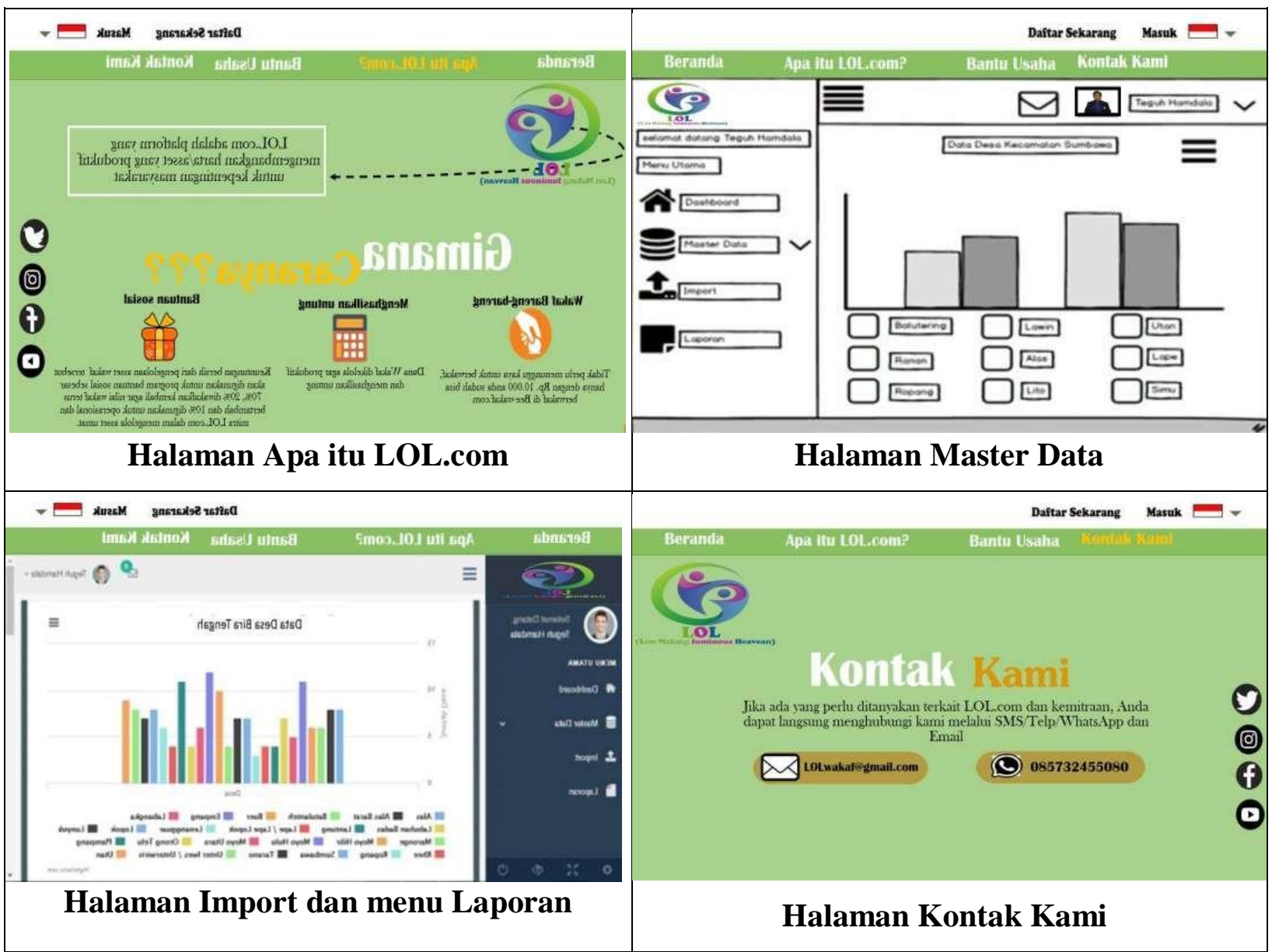

a. Masyarakat yang berkeinginan untuk berwakaf serta membantu memberikan pembiayaan UMKM ibu rumah tangga di Bira Tengah, dapat mengakses layanan pada website LOL.com melalui smartphone maupun PC.

b. Setelah masuk pada situs platform, kemudian calon wakif melakukan registrasi awal dan dilanjut proses berikutnya.

c. LOL.com memiliki enam menu utama

d. Beranda berisi data tentang Jumlah wakaf yang terkumpul dan barcord untuk melakuan wakaf yang terintegrasi dengan QRIS.

e. Halaman Bantu usaha, berisi informasi tentang usaha yang membutuhkan pembiayaan. Informasi tersebut berupa: cerita hidup calon penerima modal dan dokumentasi kegiatan usaha. Pada halaman ini, Wakif dapat langsung melakukan wakaf di usaha yang diinginkan dengan mengklik "Bantu Sekarang".

f. Halaman Apa itu LOL.com memuat informasi penjelasan platform LOL.com dan cara masyarakat umum untuk melakukan wakaf di website LOL.com

g. Halaman Kontak Kami, akan menampilkan informasi kontak admin platform website 
Rancang Bangun Strategi Pemberdayaan UMKM melalui Wakaf Produktif Berbasis Model Sharia Grameen Bank di Era New Normal

LOL.com sebagai bentuk penyediaan apabila masyarakat umum hendak menanyakan informasi lebih lanjut terkait segala hal dari LOL.com.

h. Dashboard Master Data, Import dan menu Laporan, Pada dashboard master menjelaskan terkait jumlah data penduduk desa Bira Tengah dari hasil proses penginputan data dari setiap Kepala Keluarga. Import merupakan bagian proses dari setiap tahapan dalam penyaluran dana kepada penerima. Hal ini dibuat dengan tujuan agar dana dapat tersampaikan secara transparansi serta dapat di Monitoring secara berkala. Menu Laporan merupakan hasil pelaporan dari semua proses transaksi baik pemberian maupun penerimaan dana wakaf, selanjutnya akan di analisa dan evaluasi dengan harapan sebagai perbaikan program serta sistem website ke depannya.

\section{i. Pengujian Aplikasi/Website}

Pengujian Aplikasi Monitoring Dan Evaluasi Penyaluran Dana Berbasis Web dilakukan menggunakan pengujian black box yaitu pengujian pada sistem admin. Penyerahan sistem atau perangkat lunak ke para pengguna atau pelanggan Setelah peneliti menyelesaikan tahapan-tahapan penelitian. Maka, selanjutnya peneliti menyerahkan hasil penelitian kepada pihak terkait yaitu LMI Kabupaten Sampang. Proses implementasi dan intruksi dalam LOL.com ini memerlukan beberapa kerja sama engan pihak terkait, antara lain : Pihak Interface dimana berperan dalam pendesaian serta pemrograman dalam pembuatan serta pengembangan sistem, pihak keuangan sebagai evaluasi serta analisa perkembangan dana sebagai tolak ukur kemajuan dari program web yang dibuat, dan pihak LMI sendiri sebagai wadah dalam membantu serta melindungi dari segi hukum dengan menggunakan sistem legalisasi.

\section{KESIMPULAN}

Berdasarkan penjelasan di atas dapat disimpulkan bahwa besarnya potensi wakaf di Indonesia diharapkan mampu mengentaskan berbagai permasalahan yang dihadapi. Permasalahan yang dihadapi penduduk Bira Tengah yang mayoritas perekonomian sekaligus dalam mengoptimalkan potensi besar dari wakaf, maka diperlukan sebuah solusi yang inovatif dan keberlanjutan yang dalam hal ini akan dihadirkan sebuah program yaitu LOL (Lon Malang Luminous Heaven). LOL (Lon Malang Luminous Heaven) merupakan website yang digunakan sebagai media berwakaf untuk dijadikan pinjaman modal kepada kelompok ibu rumah tangga di Desa Bira Tengah yang mengadopsi sistem Grameen Bank serta menerapkan prinsip ekonomi 
${ }^{1}$ Abd. Wahab, ${ }^{1}$ Siti Masfufa, ${ }^{2}$ Ridan Muhtadi, ${ }^{3}$ Nur Rachmat Arifin

syariah melalui mitra dengan berbagai stakeholders, seperti akademisi sebagai pihak yang memberikan pelatihan, koperasi desa sebagai pihak yang menjadi entitas, dan Laznas LMI Sampang sebagai pihak yang menampung serta merealisasikan hasil dari wakaf produktif. 
Rancang Bangun Strategi Pemberdayaan UMKM melalui Wakaf Produktif Berbasis Model Sharia Grameen Bank di Era New Normal

\section{DAFTAR PUSTAKA}

Aji, G. (2016). Studi Kelayakan Wakaf Produktif. Wahana Akademika: Jurnal Studi Islam dan Sosial, 2(1), 21-36.

Arifin, N. R., Muhtadi, R., \& Aziz, A. (2020). MANAJAMEN ISTIBDAL ATAS ASET WAKAF SEBAGAI PEMBANGUNAN EKONOMI. Filantropi: Jurnal Manajemen Zakat dan Wakaf, 1(2), 193-216.

Arifin, N. R. (2020). MANAJEMEN WAKAF SEBAGAI PEMBIAYAAN BARANG PUBLIK DAN BARANG PUBLIK CAMPURAN DI INDONESIA. Ar-Ribhu: Jurnal Manajemen dan Keuangan Syariah, 1(2), 246-264.

Badan Pusat Statistik. 2020. [Online]. Jumlah (Juta Jiwa) dan persentase penduduk miskin Indonesia 2020. Diakses melalui https://www.bps.go.id pada 19 Februari 2021.

Dwidjowijoto., R. R. W. dan R. N. (2007). Manajemen Pemberdayaan: Sebuah Pengantar dan Panduan untuk Pemberdayaan Masyarakat. Media Komputindo.

Ferdinand, A. (2006). Metode Penelitian Manajemen : Metode Penelitian Skripsi, Tesis dan Disertasi Ilmu Manajemen. Semarang: Badan Penerbit Universitas Diponegoro.

Mansur, M., Muhtadi, R., Kamali, K., \& Rofiki, A. (2020). MODEL LOCAL CULTURE TOURISM BERBASIS TANEAN LANJHANG DESA LARANGAN LUAR PAMEKASAN. PROFIT: Jurnal Kajian Ekonomi dan Perbankan Syariah, 4(2), 17-40.

Mursyid, W. dan. (2017). Wakaf \&Kesejahteraan Umat ( FilantropiIslam yang Hampir Terlupakan). Pustaka Pelajar.

Narayan-Parker, D. (2002). Empowerment and Poverty Reduction (D. Naraya (ed.)). The International Bank for Reconstruction and Development.

Odagiri, M., Cronin, A. A., Thomas, A., Kurniawan, M. A., Zainal, M., Setiabudi, W., Gnilo, M. E., Badloe, C., Virgiyanti, T. D., Nurali, I. A., Wahanudin, L., Mardikanto, A., \& Pronyk, P. (2020). Achieving the Sustainable Development Goals for water and sanitation in Indonesia - Results from a five-year (2013-2017) large-scale effectiveness evaluation. International Journal of Hygiene and Environmental Health, 230, 113584. https://doi.org/10.1016/j.ijheh.2020.113584

Qahaf, M. (2008). Tathawwuruhu Idaaratuhu wa Tanmiyyatuhu, Manajemen Wakaf Produktif. Khalifa.

Rohman, A., Hisyam, M. A., Muhtadi, R., \& Arifin, N. R. (2020, May). Construction of Waqf Istibdal Regulations for Empowering Non Productive Waqf in Indonesia. In Riau Annual Meeting on Law and Social Sciences (RAMLAS 2019) (pp. 134-137). Atlantis Press.

Sugiyono. (2014). Metodologi Penelitian Pendidikan. Alfabeta.

Yunus, M. (2013). Social business entrepreneurs are the solution (1 st editi). The future makers. 